\title{
Editorial: Security for occupational pensions
}

Consumer protection for members of occupational pension schemes has stormed up the political agenda in recent months, with revelations that a small number of companies were winding up their pension schemes leaving insufficient money to meet all scheme members' benefit entitlements. Those situations have arisen at both solvent and insolvent employers, but it is in the latter circumstances that employees can suffer the greatest hardship. In some well-publicised cases, employees have lost both their job and the pension that they have built up throughout their working life.

In such cases, employees are often left with a far smaller pension than they had expected. For those on the verge of retirement, there is no time in which to make up the shortfall between what was expected and what can be delivered. What has really rankled is that people's expectations can be disappointed quite legitimately, and this has been particularly true where solvent employers have decided to wind up the pension scheme and have then refused to meet the cost of the full benefit promises made to active and deferred members.

Here it helps to step back a bit and look at the purpose of the minimum funding requirement (MFR). It sets a minimum level of funding for defined benefit schemes on the assumption that the employer continues in business and to fund the scheme. It is not a solvency test and was not designed to ensure that schemes would have enough money in the fund to meet all liabilities if they were to wind up.

As the MFR had been introduced in the wake of the Maxwell affair, it was assumed that it protected people's pensions. But the MFR does not attempt to deliver full security for non-pensioners' benefits, principally because to do so would place too heavy a financial burden on the sponsors of defined benefit schemes. As a result, the security of members' benefits rests on a combination of the assets built up in the fund and the continued strength and commitment of the employer who underwrites the eventual cost of the benefits provided to the employees. Establishing the degree of security of the members' benefits therefore depends on the success of the scheme's investment strategy and the wellbeing of the employer.

In the UK it is common practice to invest pension scheme assets predominantly in equities. Because the value of equities is more volatile than that of bonds or gilts, the degree of security for members' benefits varies. On the positive side, schemes have historically benefited from higher returns by investing in equities, albeit while exposing the fund to greater risk. The consequences of this strategy can be especially painful when schemes are winding up. This is because pensioner benefits take priority over non-pensioner benefits, so it is the non-pensioner benefits that are most exposed to any volatility in share prices. If, as is happening at present, schemes are going 
into wind-up while the value of the equities they hold is depressed, then the payouts to non-pensioners can be particularly hard hit.

So, how should scheme members' benefits be made more secure?

Asking all pension schemes to back up their promises with bonds would be too expensive even if there were sufficient bonds to go around. The question is how you safeguard the benefits of pension scheme members without restricting employers' rights to provide benefits in the most affordable way.

Other alternatives worthy of consideration are:

- a mutual insurance fund for pension schemes

- market-based insurance

- re-jigging the order of priority that applies to members' benefit entitlements when the scheme is wound up.

\section{Commercial insurance}

Forcing pension schemes to buy insurance on the open market is currently not practical. In theory, commercial insurance should be able to get close to the fair price of the cost of the insurance by taking into account the many relevant rating factors. However, at the present time, there is virtually no market in such insurance. Moreover, in spite of a substantial credit derivatives market, it is not obvious that there is sufficient capacity to cover all UK pension funds. Administration costs could also be substantial, especially when compared with the costs of mutual insurance.

\section{Overseas comparisons}

Mutual insurance exists in various industries in the UK and is also used to provide compensation where pension schemes fail to deliver their promised benefits in Germany, Sweden and the USA. When considering this potential solution it is instructive to look at the systems employed overseas.

In the USA, where there are modest funding requirements on schemes, the compensation fund is paid for by a levy on pension schemes that is proportionate to both membership and unfunded liabilities. The levy has averaged 0.1 per cent of assets under management, although those costs have proved increasingly expensive.

The UK Government indicated its unwillingness to act as the ultimate guarantor for such a scheme in the UK when the MFR was under review in September 2000. Would the UK Government be so reticent if the retirement expectations of thousands of workers were dashed if a large UK plc went bust?

\section{PBGC in the USA}

The Pension Benefit Guaranty Corporation (PBGC) is a federal agency that was set up in 1974 to insure and protect pension benefits in private defined benefit plans. The majority of its financing comes from insurance premiums paid by companies whose plans it protects, not from taxes. The levy is based on membership and unfunded liabilities and has a current maximum of $\$ 72$ per member. However, the PBGC does have access to Federal loans, but they are expected to be paid back out of future subscriptions, so giving the PBGC an element of government backing. It is unclear what would happen if the loans were to become too big for a dwindling number of schemes to pay off.

The benefits that are paid out depend on the specific provisions of each plan, 
the legal limits, the form in which the benefit is to be paid, the retiree's age and the amounts that the PBGC can recover from the plan sponsor. The maximum annual payment that PBGC will make is $\$ 42,955$ per year for a worker who retires at age 65 . It guarantees 'basic benefits', which include pension benefits at normal retirement age, most early retirement benefits, disability benefits and certain survivor's benefits.

The PBGC may not meet employee's full retirement expectations because it places restrictions on benefit increases in the five years before the plan ends; nor does it provide inflation-linked increases. As individuals approach retirement, they have options as to the type of annuity they can receive from straight-life, certain and continuous annuities through to joint and survivor annuities. The PBGC also retains investment freedom.

\section{European alternatives}

Sweden offers a similar compensation fund, with those companies that have poorer credit ratings paying a higher rate. The levy averages 0.2 per cent of liabilities compared with 0.1 per cent of assets in the USA. Germany's system has an average levy of 0.15 per cent of liabilities with the levy being proportionate to membership.

But while the Swedish system covers all benefits, Germany's insurance system does not cover pensions for people with less than ten years service, any pension above $€ 82,000$ a year and pension increases. This still offers a far stronger degree of security than the UK's Pensions Compensation Scheme (PCS) which meets the cost of benefits only where fraud has occurred. The PCS is funded by a levy on pension schemes that is proportionate to membership. Only 90 per cent of the pension is covered by the scheme, which is run by the Pensions Compensation Board (PCB).

\section{A central discontinuance fund}

One method of operating a mutual insurance fund that is often suggested is the central discontinuance fund (CDF). This could take the form of an occupational pension scheme with trustees that would receive a transfer of assets from schemes that were winding up where the employer was insolvent. This could be an enlarged PCB, capable of imposing a levy on all defined benefit schemes, which would be required to participate. The levy would equal, in aggregate, the capital cost of pensions taken over by the PCB in that year as a result of newly undertaken pension funds in that year.

The levy could take into account the different risks of each pension scheme. This would cover the degree of under-funding, the risks in the investment strategy, but probably not the credit-rating of the sponsoring employer because a comprehensive rating system does not exist.

Ruling out payments from the scheme to the funds of solvent employers would avoid the problem of solvent employers attempting to fund schemes through risky investments in the knowledge that, if they are not successful, they have the fall-back position of the CDF.

In return for the transfer of assets, the CDF could provide benefits in accord with its own premium rates - the terms for the conversion of the pension scheme's assets into benefits payable from the CDF.

Where schemes meet the MFR, there would in theory be enough money for the CDF to meet the liabilities.

Inevitably circumstances would arise where schemes were funded below the required level at the time the scheme's 
assets were transferred to the CDF. The funding level would be below that required to pay for all benefits on a buy-out basis, so the CDF would have to be given investment freedom in order to match assets against liabilities to ensure that the liabilities can be met as they become due.

The Faculty and Institute of Actuaries (FIA) has estimated, in its 2000 report on the MFR, that there is only a small chance of the levies on employers with defined benefit schemes being more than 0.5 per cent of scheme assets, but cautioned that further research would need to be done. With defined benefit schemes having an estimated f550bn under management, this could hit employers to the combined total of $f^{2.7 b n}$ per year. When the FIA produced its report, it felt that the CDF would be unlikely to grow to more than 3 per cent of the assets of UK defined benefit schemes, but that was before the current depths of the bear market in share prices. At a time like this, it would be reasonable to expect costs to be more pronounced as businesses struggle to make ends meet.

If a large plc were to go bust, the cost to employers would be all the more significant. The likelihood is that such an occurrence would be during a recession, making the sharp increase in insurance costs all the more unpalatable for those employers forced to make payments. Moreover, if those extra premiums were significant because of the size of the insolvent employer's pension scheme, they could hasten the closure of other defined benefit schemes.

The CDF could then find itself unable to meet all the accrued benefits for which it was liable and so find itself falling back on a guarantor, be that employers or the Government.

Employers would already be paying towards the cost of the scheme and further expenses would probably call into question its viability. Getting the agreement of guarantors to act in that capacity is the principal difficulty, especially as they would be entering into a long-term agreement when the number of defined benefit schemes is falling.

\section{Moral hazard}

The Goode Report identified three areas where the existence of a compensation scheme might lead employers to take decisions that would place an intolerable burden on the scheme.

One of these acts as a strong reason for not allowing solvent employers to offload their pension scheme onto a compensation fund. If this was permitted, the employer might encourage the trustees to take a less prudent investment strategy than they otherwise would because the higher the return on the scheme's investments, the lower the costs to the employer in a balance of costs scheme. The employer stands to gain all the benefits from a high risk investment strategy while the compensation fund would meet the cost of any losses.

Secondly, if the employer gets into difficulties, it might favour other creditors over the pension scheme in the knowledge that the pension scheme would be protected by the compensation scheme if it became insolvent.

A third situation could arise where an employer offers scheme benefit improvements as an alternative to wage increases. If the improvements applied to past service or to pensions in payment, they might create or enlarge a deficit in the pension scheme that subsequently has to be met from the compensation scheme.

\section{A way through the minefield}

Is the goal of absolute security for members of occupational pension 
schemes at an affordable cost to employers and staff a Holy Grail? Or can a legislative tiptoe be accomplished which introduces a system that maintains the affordability of defined benefit schemes, secures the benefits of their members and which cannot be used as an escape hatch from promises that employers regret making.

The NAPF would like to see the Government undertake a detailed study to assess the cost of such mutual insurance. It has to be recognised that the American experience has found that the cost of the insurance has become increasingly expensive. Ultimately any system put in place would almost certainly need the Government as the ultimate guarantor.

If insurance is to be dismissed, it seems that the best alternative is to amend the priority orders on winding up so that there is greater protection for those approaching retirement. Other methods that could help preserve schemes would be:

- to give trustees a more active role in monitoring the solvency of the scheme for which they are responsible

- to give actuaries greater formal responsibilities with regard to the future funding basis of defined benefit schemes

- the active monitoring of scheme solvency levels by the regulator where potential problems are identified

- increased and more effective communication with scheme members regarding the risks and security of their scheme.

With a few high profile cases in the media, the issue of how to safeguard the rights of members of occupational pension schemes is now higher than at any time since the Maxwell affair. Yet the choice still remains as hard to take. One option is higher costs through paying for insurance and, in the longer term, lower benefits as employers pull the plug on defined benefit schemes. The alternative is the same level of security, differently shared out between scheme members, through changes to the priority orders on winding-up. Both have their drawbacks.

Paul Barton

Members Services Manager National Association of Pension Funds

(NAPF)

London, UK 